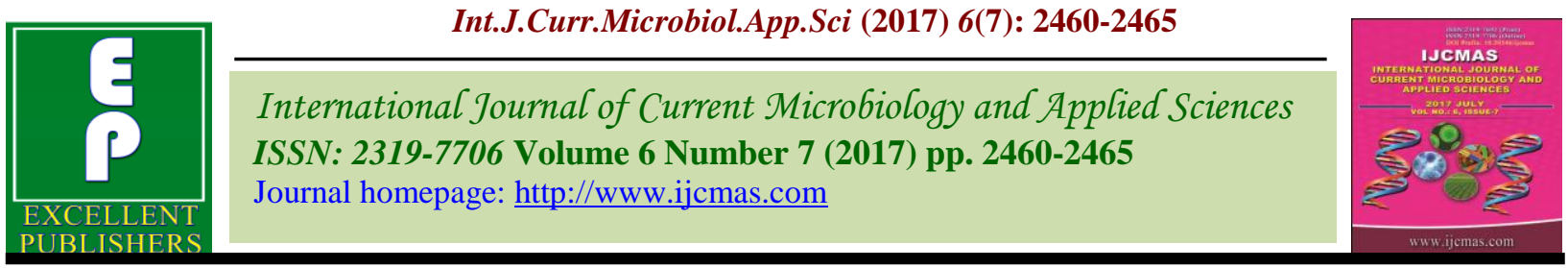

Original Research Article

https://doi.org/10.20546/ijcmas.2017.607.349

\title{
Information Seeking Behavior about Animal Husbandry Enterprise Holders of Farmer's Interest Groups
}

\author{
M. Kumari ${ }^{1 *}$, C.K. Timbadia ${ }^{2}$ and N.R. Baria ${ }^{1}$ \\ ${ }^{1}$ Department of Extension Education, N.M. College of Agriculture, NAU, Navsari, Gujarat, India \\ ${ }^{2}$ KVK, Navsari, Gujarat, India \\ *Corresponding author
}

A B S T R A C T

Keywords

Information

seeking behavior,

Animal husbandry,

Livestock, Farmer

Interest Group

Article Info

Accepted:

26 June 2017

Available Online:

10 July 2017
A study was conducted in Navsari district of South Gujarat to know the level of information seeking behaviour of animal enterprise holders of FIGs. A sample of 120 FIGs members was selected for the study. This study revealed that majority (84.17 per cent) of the FIGs members had medium level of information seeking behaviour followed by those with lower level (14.17 per cent) and higher level (1.67 per cent) information seeking behaviour. It could be observed that family size, land holding, annual income, animal husbandry experience, economic motivation and innovativeness did not show any significant relationship with information seeking behaviour of FIGs members. Whereas, education, social participation, livestock possession, risk orientation and scientific orientation showed positive and significant relationship and age showed negative and significant relationship with information seeking behaviour of FIGs members at 0.05 level of probability.

\section{Introduction}

Livestock rearing is an integral part of agriculture in India. The Indian dairying enterprise has made a remarkable progress in the last three decades. Gujarat has strong stricture of milk co-operatives and playing significantly in milk collection and marketing in India. "To live effectively is to live with information". Effective fulfillment of information needs can make the difference between life and death (McGarry, 1993).Information as an enterprise is important for the production process especially for agricultural production and marketing of agricultural produce. Cattle farmers have varying needs that range from information on the disease status of animals which is very crucial and can contribute to a large number of herd die offs when ignored or pose as a threat to the wellbeing of humans. Cattle farmers also need information on good animal husbandry practices, new emerging technologies, market related information and information on agriculture policies. The assessment of the information needs and seeking behaviour of cattle farmers is essential for assisting them to access and use information resources required for high production levels and equally to assist the relevant authorities in charge of disseminating information to come up with better agricultural implementation strategies. Keeping this view in mind, the present study 
conducted "Information seeking behaviour about animal husbandry enterprise holders of farmer's interest groups (FIGs) of Navsari district" was undertaken. The specific objectives were to:

To study information seeking behavior of the members of FIGs about animal husbandry enterprise.

To study the relationship between profile of animal husbandry enterprise holder of FIGs and their information seeking behavior.

\section{Materials and Methods}

The present study was under taken in Navsari district of Gujarat. Navsari district has six talukas viz., Chikhli, Gandevi, Jalalpore, Khergam, Navsari and Vansda. The list of FIGs obtained from Project Director, ATMA, Navsari and from that the FIGs classified under animal husbandry selected. Random sampling method applied to obtain 120 respondents from the obtained list. An Expost facto research design was adopted for the study. In line of the objectives, the interview schedule was prepared and respondents were interviewed at their home and farms. The independent and dependent variables were considered and measured through appropriate scales and specially developed structured schedules by the investigator in light of the suggestions of the experts. A teacher made scale was developed with the help of faculty members of extension education discipline to measure, the information seeking behaviour for that the scoring procedure used is 3 for 'regular', 2 for 'occasional' and 1 for 'never' consulting the source to seek the information. Respondents can be categorized into three categories namely, 'low', 'medium' and 'high' by using mean and standard deviation. The collected data were classified, tabulated and inferences were drawn after subjecting the data to appropriate statistical analysis which led to the following major findings.

\section{Results and Discussion}

\section{Information seeking behaviorof the figs} members

The data in Table 2 revealed that majority (84.17 per cent) of the FIGs members had medium level of information seeking behaviour followed by those with lower level (14.17 per cent) and higher level (1.67 per cent) information seeking behaviour. Thus, the majority of the of the FIGs members had medium level information seeking behaviour which may be due to the handy availability of communication devices like telephone, mobile and internet services which facilitate easy contact with experts, veterinary doctors and extension workers for proper guidance and up to date information to manage their dairy farms efficiently. Similar finding were reported by Nande et al., (2009), Lawrence and Ganguli (2012), Rathod et al., (2012), Kavithaa et al., (2014), Gamit et al., (2015), and Chaurashiya et al., (2016).

\section{Relationship between profile of the animal husbandry enterprise holder of figs and their information seeking behavior}

The data manifested in table 3 revealed that the education of FIGs members $\left(0.1986^{*}\right)$, social participation $\left(0.1810^{*}\right)$, livestock possession $\left(0.2145^{*}\right)$, risk orientation $\left(0.2043^{*}\right)$ and scientific orientation $\left(0.2027^{*}\right)$ were found positive and significant correlated with their information seeking behaviour. On the other hand age $\left(0.1850^{*}\right)$ was found negative and significant correlated with their information seeking behaviour. On the other hand family size $\left(0.0671^{\mathrm{NS}}\right)$, land holding $\left(0.0573^{\mathrm{NS}}\right)$, annual income $\left(0.0145^{\mathrm{NS}}\right)$, animal husbandry experience $\left(0.6698^{\mathrm{NS}}\right)$, economic motivation $\left(0.1125^{\mathrm{NS}}\right)$ and innovativeness $\left(0.2095^{\mathrm{NS}}\right)$ were found non-significantly correlated with their information seeking behaviour. This finding is in conformity with Nande et al., (2009). 
Table.1 Information about taluka, villages and respondents covered under the study

\begin{tabular}{|c|c|c|c|}
\hline Sr. & Name of Taluka & Name of village & Respondents size \\
\hline \multirow{2}{*}{1.} & \multirow{2}{*}{ Navsari } & Partapore & 10 \\
\hline & & Magar & 10 \\
\hline \multirow{2}{*}{2.} & \multirow{2}{*}{ Chikhli } & Ranverikalla & 10 \\
\hline & & Kanbhai & 10 \\
\hline \multirow{2}{*}{3.} & \multirow{2}{*}{ Vansda } & Limzar & 10 \\
\hline & & Upsal & 10 \\
\hline \multirow{2}{*}{4.} & \multirow{2}{*}{ Gandevi } & Devsar & 10 \\
\hline & & Mendhar & 10 \\
\hline \multirow{2}{*}{5.} & \multirow{2}{*}{ Jalalpore } & Abrama & 10 \\
\hline & & Mandir & 10 \\
\hline \multirow{2}{*}{6.} & \multirow{2}{*}{ Khergam } & Panikhadak & 10 \\
\hline & & Jamanpada & 10 \\
\hline & & & 120 \\
\hline
\end{tabular}

\begin{tabular}{|c|l|c|}
\hline Sr. No. & \multicolumn{1}{|c|}{ Category } & Range \\
\hline 1 & Low level of information seeking behaviour & Less than (Mean - Standard deviation) \\
\hline 2 & Medium level of information seeking behaviour & In Between (Mean \pm Standard deviation) \\
\hline 3 & High level of information seeking behaviour & More than (Mean + Standard deviation) \\
\hline
\end{tabular}

Table.2 Distribution of FIGs members according to their information seeking behavior

\begin{tabular}{|c|c|c|c|}
\hline Sr. & Categories of information seeking behaviour & Frequency & Per cent \\
\hline $\mathbf{1 .}$ & Lower level & 17 & 14.17 \\
\hline $\mathbf{2 .}$ & Medium level & 101 & 84.17 \\
\hline $\mathbf{3 .}$ & Higher level & 2 & 1.67 \\
\hline \multicolumn{2}{|c|}{ Total } & $\mathbf{1 2 0}$ & $\mathbf{1 0 0 . 0 0}$ \\
\hline
\end{tabular}

$(\mathrm{Mean}=42.6 / \mathrm{SD}=7.25)$

Table.3 Relationship between profile of FIGs members and their information seeking behavior

\begin{tabular}{|c|l|c|}
\hline \multicolumn{2}{|c|}{ Independent variables } & Coefficient of correlation $(\boldsymbol{r})$ \\
\hline Sr. & \multicolumn{1}{|c|}{} & $-0.1850^{*}$ \\
\hline $\mathbf{1 .}$ & Age & $0.1986^{*}$ \\
\hline $\mathbf{2 .}$ & Education & $0.0671^{\mathrm{NS}}$ \\
\hline $\mathbf{3 .}$ & Family size & $0.1810^{*}$ \\
\hline $\mathbf{4 .}$ & Social Participation & $0.0573^{\mathrm{NS}}$ \\
\hline $\mathbf{5 .}$ & Land holding & $0.2145^{*}$ \\
\hline $\mathbf{6 .}$ & Livestock possession & $0.0145^{\mathrm{NS}}$ \\
\hline $\mathbf{7 .}$ & Annual income & $0.6698^{\mathrm{NS}}$ \\
\hline $\mathbf{8 .}$ & Animal husbandry experience & $0.2095^{*}$ \\
\hline $\mathbf{9 .}$ & Innovativeness & $0.2043^{*}$ \\
\hline $\mathbf{1 0 .}$ & Risk orientation & $0.2027^{*}$ \\
\hline $\mathbf{1 1}$. & Scientific orientation & $0.1125^{\mathrm{NS}}$ \\
\hline $\mathbf{1 2 .}$ & Economic motivation & \\
\hline
\end{tabular}

(* Significant at 0.05 level, NS Non significant) 
Fig.1 Distribution of FIGs members according to their information seeking behaviour

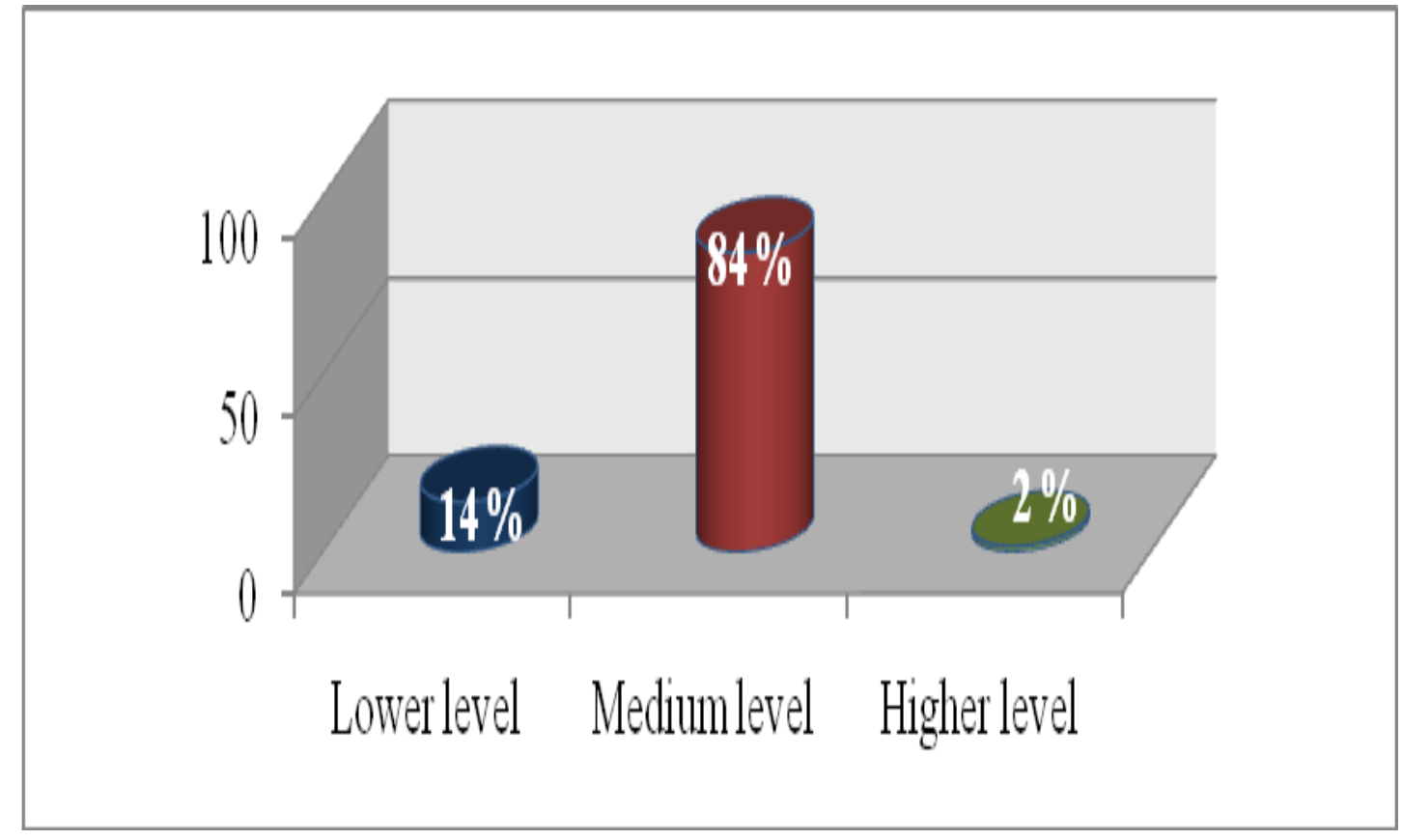

Fig.2 Relationship between independent variables of FIGs members and Their information seeking behavior

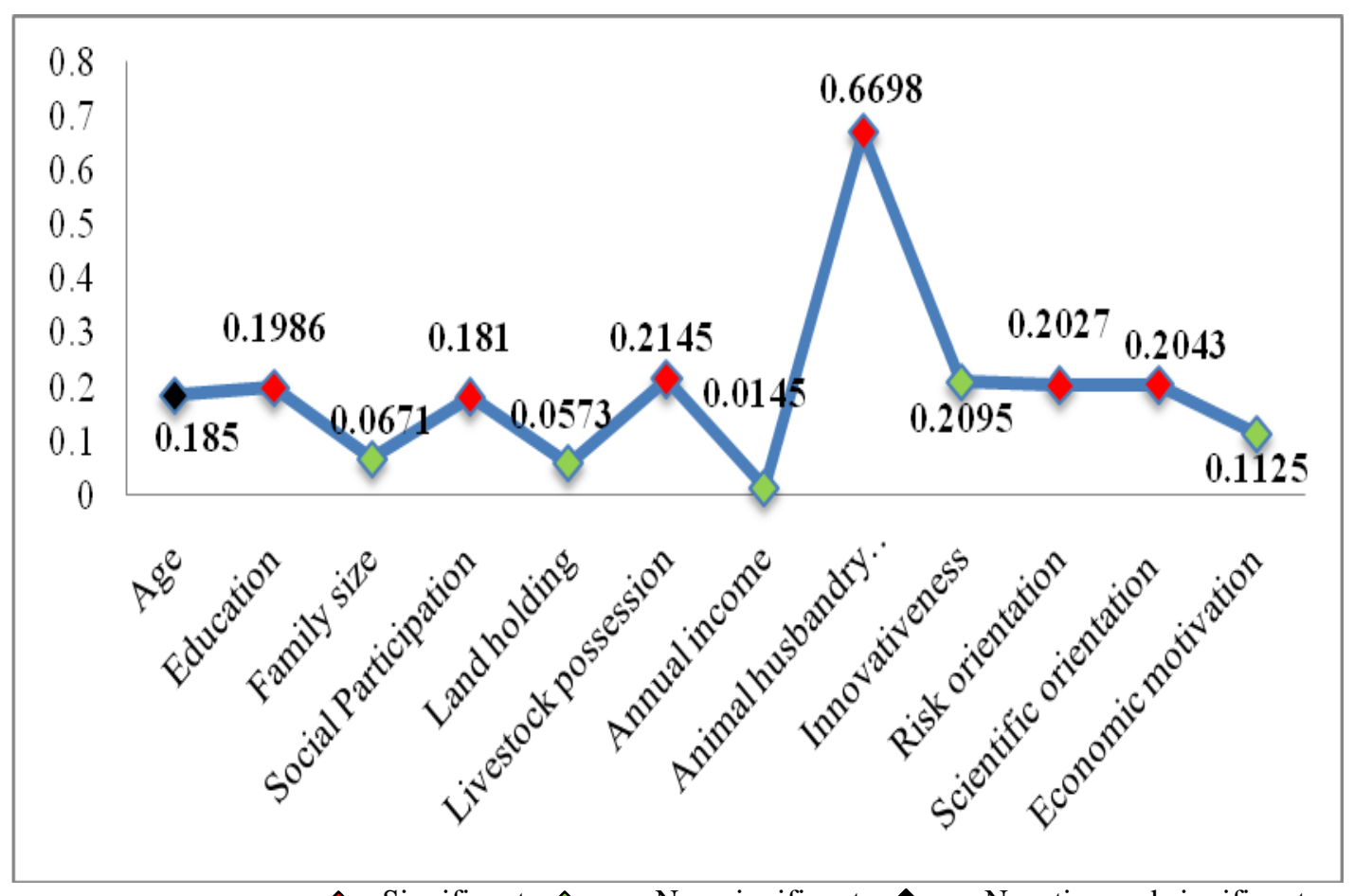


Fig.3 Empirical model depleting relationship between independent variable and Information seeking behaviour

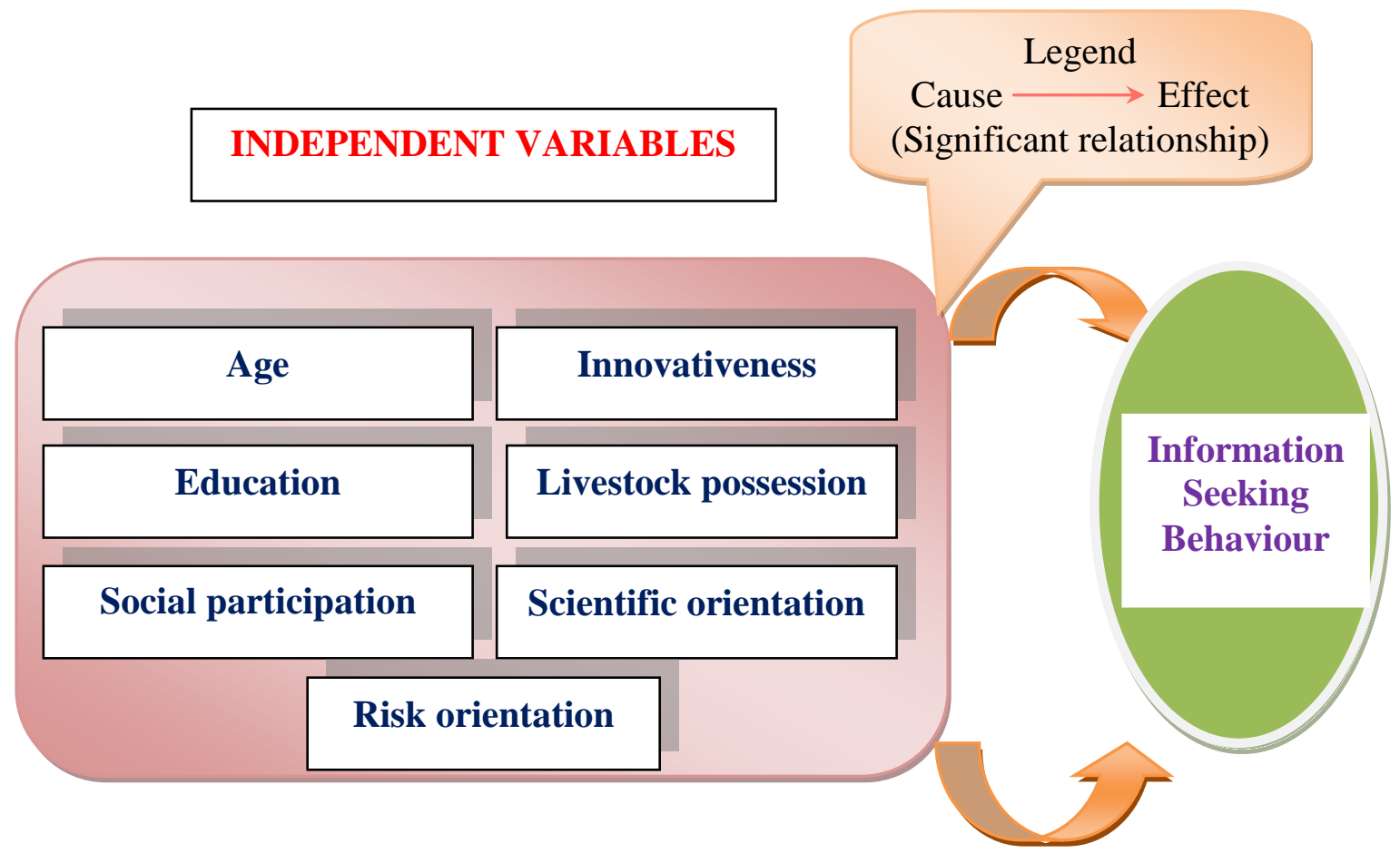

The study revealed that majority of the FIGs members belonged to medium level information seeking behaviour category followed by low and high level. Hence, special consideration is required to information seeking behaviour in FIGs members. Therefore, efforts should be made to increase the level of information seeking behaviour through awareness and training programmes, demonstrations, tours, field visits etc., for socio economic development of the FIGs members. Information seeking behaviour showed non-significant relationship with family size, land holding, annual income, animal husbandry experience, economic motivation and innovativeness of the FIGs members. However, education, social participation, livestock possession, risk orientation and scientific motivation were found positively and significantly related with information seeking behavior of FIGs members. Whereas, age was found negatively and significantly related with information seeking behavior of FIGs members of animal husbandry enterprise holder.

In conclusion, Information is essential elements of today livestock management and we can't make our agricultural profitable without it. So, based on the study it can be concluded that that majority of the FIGs members belonged to medium level information seeking behaviour category followed by low and high level. Hence, special consideration is required to information seeking behaviour in FIGs members. Therefore, efforts should be made to increase the level of information seeking behaviour through awareness and training programmes, demonstrations, tours, field visits etc., for socio economic development of the FIGs members. Information seeking behaviour showed non-significant relationship with family size, land holding, annual income, 
animal husbandry experience, economic motivation and innovativeness of the FIGs members. However, education, social participation, livestock possession, risk orientation and scientific motivation were found positively and significantly related with information seeking behavior of FIGs members. Whereas, age was found negatively and significantly related with information seeking behavior of FIGs members of animal husbandry enterprise holder.

\section{References}

Chaurasiya, K. K. Badodiya, S. K. Somvanshi, S. P. S and Gaur, C. L. 2016. Entrepreneurial behavior of dairy farmers in Gwalior district of Madhya Pradesh. Indian Journal of Dairy Science 69(1): 113-115.

Gamit, M. P., Durgga R. V., Bhabhor, I. N., Tyagi, K. K. and Rathod, A. D. 2015. Entrepreneurial behaviour of dairy farmers in Surat district of South Gujarat,
International Journal of Advanced Multidisciplinary Research 2(8): 50-56.

Kavithaa, N. V., Rajkumar, N. V. and Lakshmi, C. M. (2014).Information seeking behavior of dairy farmers. International journal of science, Environment and Technology.3(4): 1502-1506.

Lawrence, C. and Ganguli, D. 2012.Entrepreneurial Behaviour of Dairy Farmers in Tamil Nadu. Indian Research Journal of Extension Education, 12(1): 66-70.

Nande, M.P., Gawande, S. H., Patil, A. M. and Khode, N.V. 2009. Information Seeking Behaviour of Dairy Farmers in Nagpur District of Maharashtra. Journal of Community Mobilization and Sustainable Development, 4(I): 99-102

Rathod, P., Nikam, T.R., Landge, S. and Hatey, A. 2012. Entrepreneurial behaviour of dairy farmers in western Maharashtra, India. International Journal of Communication \& Business Management, 5(2): 115-121.

\section{How to cite this article:}

Kumari, M., C.K. Timbadia and Baria, N.R. 2017. Information Seeking Behavior about Animal Husbandry Enterprise Holders of Farmer's Interest Groups. Int.J.Curr.Microbiol.App.Sci. 6(7): 2460-2465. doi: https://doi.org/10.20546/ijcmas.2017.607.349 